\title{
Commentary: You have to work hard...to make it simple
}

Heidi B. Nafday, MD, and Eugene A. Grossi, MD

"Simple can be harder than complex: You have to work hard to get your thinking clean to make it simple. But it's worth it in the end because once you get there, you can move mountains."

- Steve Jobs

In their review meta-analysis "Treatment Options for Ischemic Mitral Regurgitation: A Meta-Analysis," Nappi and colleagues ${ }^{1}$ take on a challenging process-interpreting the litany of high-quality outcomes research studies on various treatments for ischemic mitral regurgitation. Yes, this is a complex field, as evidenced by their Table 1 . Take the time to delve into this table-in particular looking at different strata of preoperative left ventricular dimensions. It helps elucidate where in the ventricular "time line" of the ischemic mitral regurgitation process various therapies are being applied. From there, jump to the authors' punchline-Figure 6 . This graphic puts it all together, showing us where we can expect to get the best result for a given patient and where different interventions have been found equivocal. That is the beauty of this report- the authors have done the hard work of making it clean and simple. With these interpretations, the reader has the power to apply these therapies to the appropriate patient and to

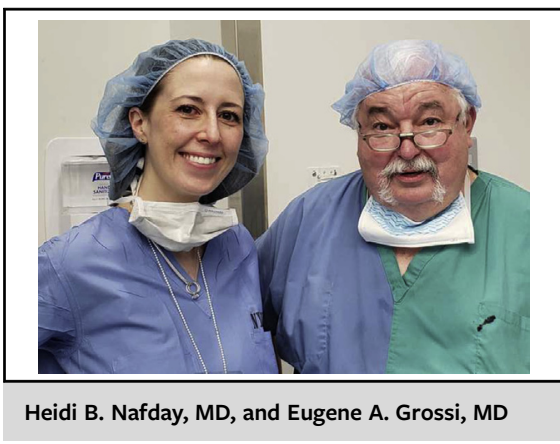

CENTRAL MESSAGE

Distilling the knowledge gained

from high-quality studies is a

challenging process that allows

others to apply it for complex

clinical scenarios.

understand the clinical situations in which no one therapy has been shown to be superior. The latter cases remain the most frustrating as we strive to do the best by our patients and apply the most sophisticated evidence available.

\section{Reference}

1. Nappi F, Antoniou GA, Nenna A, Michler R, Benedetto U, Avtaar Singh SS, et al Treatment options for ischemic mitral regurgitation: a meta-analysis. J Thorac Cardiovasc Surg. 2022;163:607-22.e14.

From the Department of Cardiothoracic Surgery, NYU Langone Health, New York, NY.

Disclosures: The authors reported no conflicts of interest.

The Journal policy requires editors and reviewers to disclose conflicts of interest and to decline handling or reviewing manuscripts for which they may have a conflict of interest. The editors and reviewers of this article have no conflicts of interest.

Received for publication June 15, 2020; accepted for publication June 15, 2020; available ahead of print June 30, 2020.

Address for reprints: Eugene A. Grossi, MD, Department of Cardiothoracic Surgery, NYU Langone Health, 530 First Ave, Suite 9V, New York, NY 10016 (E-mail: Eugene.Grossi@nyulangone.org).

J Thorac Cardiovasc Surg 2022;163:623

$0022-5223 / \$ 36.00$

Copyright (c) 2020 Published by Elsevier Inc. on behalf of The American Association

for Thoracic Surgery

https://doi.org/10.1016/j.jtcvs.2020.06.071 